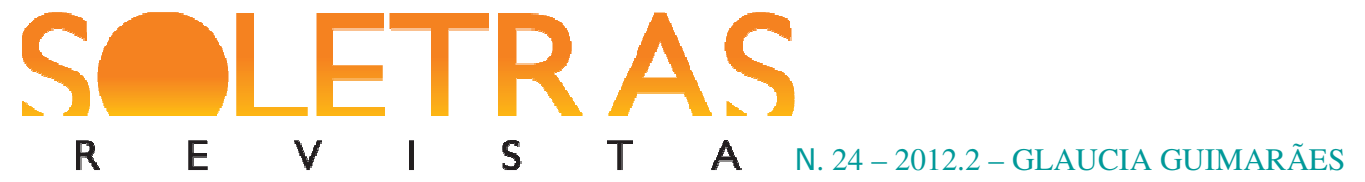

\title{
A articulação de linguagens na leitura de textos na universidade ${ }^{1}$
}

Glaucia Guimarães ${ }^{2}$

Resumo: Este artigo aborda a articulação palavra, imagem e som na leitura de textos na universidade. Com base nas reflexões acerca deste objeto, relata práticas de leitura de textos de literatura infantil, já que estes revelam grande legado na articulação de linguagens. $\mathrm{O}$ artigo se divide em seis seções. Na primeira, indica a complexidade dos textos configurados por meio de linguagens. Na segunda, questiona a acepção de que as imagens, juntas ao texto escrito, podem realizar o que as palavras não conseguem fazer, facilitando sua leitura. A partir daí, fundamentado na análise crítica de discurso, caracteriza os modos de articulação de linguagens na produção e na legitimação de sentidos hegemônicos. Na seção seguinte sublinha o legado na articulação de linguagens que historicamente os livros infantis revelam. Na quinta seção relata uma proposta de leitura crítica de textos contemporâneos desenvolvida na universidade com livros de literatura infantil. Em suas considerações finais, reitera que a relação dos sujeitos com o universo simbólico não se dá apenas por uma via - a verbal ou imagética ou sonora -, mas, considerando seu contexto histórico-social, pela articulação destas linguagens, sejam elas desenvolvidas dentro ou fora das instituições de ensino. É necessário, portanto, trabalhar com a relação sujeito e universo simbólico, considerando a literatura infantil como resistência ao aprisionamento em que o presente nos confina, pensando novos sentidos para além dos hegemônicos, inventando novas maneiras de existir.

Palavras-chave: Articulação de linguagens. Leitura. Imagem.

\section{Os pássaros e as leituras}

\author{
Pássaros \\ Os poemas são pássaros que chegam \\ não se sabe de onde e pousam \\ no livro que lês. \\ Quando fechas o livro, eles alçam voo \\ como de um alçapão. \\ Eles não têm pouso \\ nem porto \\ alimentam-se um instante em cada par de mãos \\ e partem. \\ E olhas, então, essas tuas mãos vazias,
}

\footnotetext{
${ }^{1} \mathrm{O}$ artigo foi uma palestra pronunciada no III Seminário de Estudos Literários do Programa de Pós-Graduação em Estudos Literários da Faculdade de Formação de Professores da UERJ, nos dias 23 e 24-10-2012.

${ }^{2}$ Glaucia Campos Guimarães é Professora adjunta da Universidade do Estado do Rio de Janeiro, do Programa de Pós-graduação em Educação Processos Formativos e Desigualdades Sociais da Faculdade de Formação de Professores da UERJ. Líder do Grupo de pesquisa "Linguagens, Leituras e tecnologias na escola" e pesquisadora participante do Grupo de Pesquisa "Formação de professores, processos e práticas educativas". Autora de "TV e educação na sociedade multimidiática: o discurso sedutor em imagem, som e palavra", publicado pela Editora Quartet/FAPERJ; “TV e escola: discursos em confronto”, publicado pela Cortez; entre outros.
} 
$\begin{array}{llllllll}R & \text { E } & \boldsymbol{V} & \mathbf{I} & \mathbf{S} & \mathbf{T} & \mathbf{A} & \text { N. } 24-2012.2-\text { GLAUCIA GUIMARÃES }\end{array}$

no maravilhoso espanto de saberes que o alimento deles já estava em ti...

Mário Quintana (1980)

Se um poema pode seduzir-nos tanto como este de Mário Quintana, imaginem se viesse acompanhado de imagens e sons?

Se somente por meio da linguagem verbal já podemos nos sentir encantados, talvez a retórica de outras linguagens articuladas ao escrito possa intensificar nosso envolvimento. Mas, se por um lado é muito bom comovermo-nos e nos sentir cativados por um texto, por outro pode ser importante analisar de onde vem tal fascínio, para não embarcar em paixões ilusórias ou que não têm a ver com nossa história.

Para ir além da paixão efêmera e incorporar o lido como experiência, é necessário analisar e nos apropriar, encontrando outros sentidos que ainda não foram lidos e experimentados. Como afirma Orlandi (1990, p. 12), "compreender é saber que o sentido pode ser outro", diferente daquele que parece ser óbvio ou "o correto".

A atribuição de outros sentidos diz respeito a um movimento de apropriação do texto pelo leitor. E é também neste processo que suas experiências podem ser transportadas para o texto, produzindo outra prática discursiva, isto é, outra prática social. Como a poesia de Mário Quintana sugere, a beleza de um poema configura-se nas diversas possibilidades que o poema pode suscitar em cada sujeito, isto é, a beleza percebida em um poema é, pois, a poesia do sujeito que o lê.

Então, se considerarmos que cada uma das matérias semióticas significa a seu modo, já que não podemos, por exemplo, traduzir uma música em palavras (ORLANDI, 1995), suas 'junturas' também podem ampliar as possibilidades de compreensão.

No entanto, vale ressaltar que a articulação de linguagens nos textos contemporâneos nem sempre amplia estas possibilidades. Ao contrário, os efeitos de sentido produzidos pela tensão das linguagens podem contribuir para orientar as leituras, parecendo que uns poucos sentidos pareçam óbvios.

E esta concepção sugeriu uma das condições fundamentais para a construção de estratégias de leitura nas instituições de ensino ou fora delas: a análise dos efeitos de sentidos que podem ser produzidos na articulação de linguagens. 


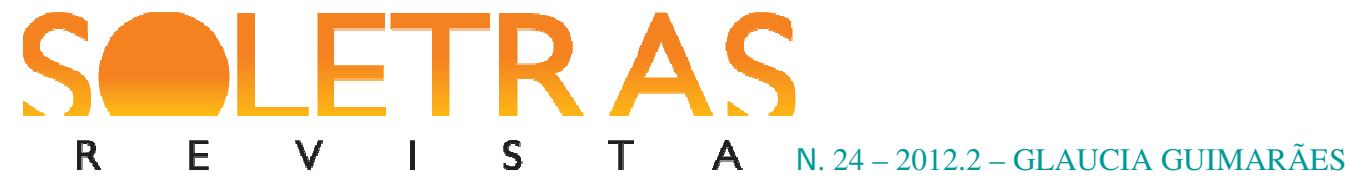

\section{Textos que articulam linguagens são mais fáceis de ler?}

Com a popularização das tecnologias de informação e comunicação, popularizaram-se também os textos por elas difundidos, geralmente compostos por palavras articuladas a imagens e, por várias vezes, a sons. Em um rápido giro ao nosso redor podemos observá-los sendo veiculados em diversas mídias, como a televisão, jornais, revistas, livros (geralmente os voltados para a área de artes ou os livros de literatura infantil), internet, celular. Com as características de articular linguagens e serem difundidos em diversas mídias, denominamos estes textos de multimidiáticos (GUIMARÃES, 2010).

Para quem ainda não domina a lógica da leitura e da escrita, estes textos podem "facilitar a leitura", já que a ilustração, por vezes, pode servir como apoio para se decodificar a palavra escrita. Helena Alexandrino (2012, p. 109), ilustradora de livro infantil, lembra que para ela "o mundo das letras" lhe foi essencialmente apresentado pela ilustração: "Eu não sabia ler, mas elas davam uns livrinhos ilustrados, aqueles de jornaleiro, e eu ficava olhando, olhava também as palavras; tanto que, quando entrei na escola, já estava muito familiarizada com as letras".

Fora esta fase, a leitura de um texto que articula linguagens geralmente só é concebida como mais "fácil", quando se considera leitura como decodificação ou como desvelamento do que o autor quis dizer. No entanto, em nossa perspectiva, leitura é negociação de sentidos entre interlocutores em determinado contexto histórico-social. O texto não tem uma única significação em si. Seus sentidos são atribuídos por seu autor, bem como por seu leitor. Sobre esta antiga questão Barthes (1992, p. 38) afirma: "há um divórcio impiedoso que a instituição literária mantém entre o fabricante e o usuário do texto, seu proprietário e seu cliente, seu autor e leitor" ; além disso, "sabemos que, para devolver à escrita o seu devir, é preciso inverter o seu mito: o nascimento do leitor tem de pagar-se com a morte do Autor".

Portanto, histórias, contextos, lugares sociais dos supostos autores e leitores participam da produção de sentido de qualquer texto. Os diferentes sentidos possíveis atribuídos ao texto podem ser infinitos e vão depender das condições de produção do texto e da leitura.

Em nosso ponto de vista, dentre estas condições de produção de sentidos estão os modos de articulação de linguagens, tanto na produção, quanto na leitura de um texto multimidiático. Neste tipo de texto, o modo de articulação de linguagens tende a orientar a produção de um sentido em detrimento de diversos outros. 
$\begin{array}{llllllll}R & \text { E } & \boldsymbol{V} & \mathbf{I} & \mathbf{S} & \mathbf{T} & \mathbf{A} & \text { N. } 24-2012.2-\text { GLAUCIA GUIMARÃES }\end{array}$

Portanto, considerando os modos de articulação de linguagens, ao invés de facilitar, podem tornar a leitura mais complexa, com grandes chances de contribuir para legitimar sentidos hegemônicos.

Uma seguidora de um $b \log ^{3}$ sobre livros para jovens, de uma forma bastante simples, registra que nem sempre a imagem pode ajudar a fazer leituras que possibilitem a observação de vários pontos de vista. Ao contrário, pode fazer com que um sentido possa ser "mais lido" que outros: "[...] eu não gosto de ler livros com figuras, porque já passei dessa fase. Estou acostumada com livros sem figura nenhuma. Mas às vezes só eh legal ter uma figura pra gente ter ideia do que o autor estava pensando".

Compreendendo leitura em sua acepção mais ampla - como negociação de sentidos entre interlocutores que ocupam lugares determinados sócio e historicamente - a articulação de linguagens pode dificultar a atribuição de outros sentidos diferentes do hegemônico. Em outras palavras, as linguagens não funcionam como transmissores de informações, mas como discurso, isto é, efeito de sentido entre interlocutores em um contexto histórico-social. Neste jogo, os modos de articulação de linguagens vão orientando de forma mais complexa os sentidos na interação social entre interlocutores. Portanto, participam da prática social, o que significa, com respaldo nas palavras de Fairclough (2001), que discurso e mudança social estão profundamente relacionados.

\section{Modos de articulação de linguagens na produção de sentidos}

Para tentarmos compreender como palavras, imagens e sons articulados produzem sentidos, partimos do pressuposto de que o contexto, os interlocutores e a "consistência significativa" das diferentes linguagens articuladas participam do processo de significação.

$\mathrm{Na}$ abordagem das diferentes linguagens, Orlandi (1995, p.7) destaca a noção de "consistência significativa", isto é, cada linguagem significa a sua maneira e uma não traduz a outra. A autora explica:

[...] há coisas que podem ser melhor 'ditas' em palavras, outras através das imagens, assim por diante e uma nunca traduz integralmente a outra. Por este motivo, elas não são transparentes em sua matéria, não são redutíveis ao verbal, embora sejam intercambiáveis, sob certas condições.

\footnotetext{
${ }^{3}$ http://www.livrosechocolate.com.br/2012/08/books-1-livros-ilustrados.html. Acesso em dezembro de 2012.
} 
$\begin{array}{llllllll}R & \text { E } & \boldsymbol{V} & \mathbf{I} & \mathbf{S} & \mathbf{T} & \mathbf{A} & \text { N. } 24-2012.2-\text { GLAUCIA GUIMARÃES }\end{array}$

Com efeito, uma linguagem não traduz a outra; mesmo quando, por exemplo, a imagem é colocada junto ao texto verbal com a intenção de ilustrar, ela abre um leque de significações que não se prendem somente ao texto verbal.

Portanto, em qualquer processo de significação, quando se articulam linguagens, elas não são apenas coexistentes, como afirma Nunes (1999), não são complementares, como defende Barthes (2011) e nem apenas justapostas, como aponta Maurice Sendak apud Linden (2011, p. 161). Elas se articulam orientando sentidos. Não apenas significam, comunicam, mas demarcam: tendem a conduzir sentidos hegemônicos, histórico e socialmente reproduzidos (FAIRCLOUGH, 2001).

Com base em Barreto (2002), identificamos três modos básicos de articulação de linguagens: (1) a convergência das linguagens apontando para um mesmo sentido; (2) a divergência entre linguagens marcando sentidos diferentes; e (3) a contiguidade de linguagens, aproximando no espaço ou no tempo sentidos diversos.

A articulação por convergência pode ser verificada, por exemplo, em textos de publicidade de destinos turísticos, em que tanto as palavras, os sons, quanto as imagens reforçam o lazer que oferecem, de modo a favorecer a venda de pacotes. Neste modo de articulação, palavras, imagens e sons funcionam como orientação da leitura em apenas um sentido, dentre muitos possíveis. Assim, uma imagem polissêmica, sendo excessivamente apresentada pela mídia, pode ser associada a uma frase ou produto, a ponto de escutarmos “[...]é isso aí!” e lembrarmos, de imediato, da imagem da Coca-Cola.

Por sua vez, a articulação por divergência ocorre quando as linguagens utilizadas sugerem perspectivas diversas, de modo que ouvir ou ver, alternativamente, favorecerá a captação de um, de outro ou, ainda, de outros sentidos. O efeito de sentido produzido pode ser, por um lado, mais polissêmico, por apontar para vários sentidos ao mesmo tempo, ou, por outro, mais parafrástico, quando uma linguagem nega, apaga e silencia a outra para posteriormente associá-la em um movimento de fixação de sentidos, ideológico por excelência.

Finalmente, o terceiro modo de articulação de linguagens - a contiguidade - se caracteriza pela interferência na produção de sentidos produzida pela proximidade entre textos e linguagens referentes a assuntos distintos. Por exemplo, a capa de $O$ Globo, de 13 de maio de 2012, aproxima a imagem de uma normalista negra e grávida, que ilustra reportagem sobre gravidez na adolescência, à manchete escrita de outra matéria - "Negros só ganham mais em $4 \%$ das profissões". Esta proximidade pode orientar a leitura, atribuindo a identificação à 


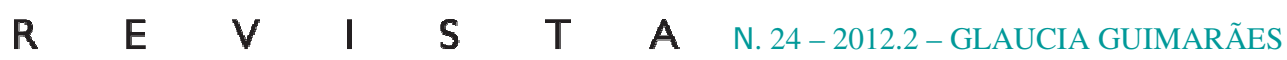

profissão de professor como uma das poucas carreiras em que negros podem ganhar mais que brancos, reforçando mutuamente a desvalorização social do negro e da profissão.

\section{Figura $1^{4}$}

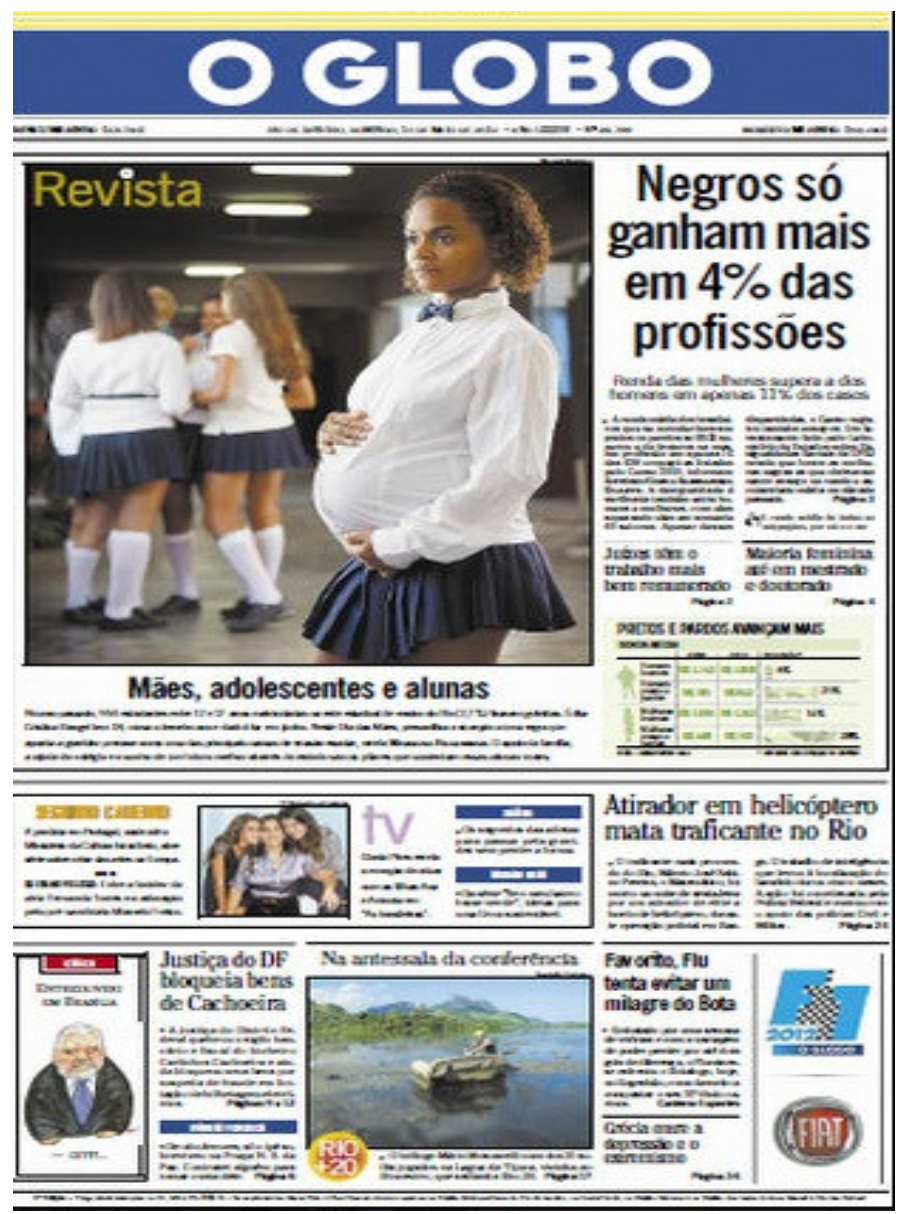

\section{A literatura infantil e seu legado na articulação de linguagens}

Desde as primeiras obras identificadas como literatura infantil, a articulação imagem e palavra - e mais tarde som e imagem em movimento - vem sendo experimentada. Trazer, aqui, uma breve história da literatura infantil, portanto, nos possibilita observar o legado que ela tem desenvolvido no que diz respeito à articulação de linguagens em textos.

A partir da primeira metade do século XIX, predominava o livro com poucas figuras, ilustrado por algumas imagens em páginas isoladas e o texto escrito era considerado o principal. Diversas inovações técnicas, como a arte da xilogravura, viriam a favorecer a mudança de concepções, o que repercutiu na configuração das imagens dos livros.

\footnotetext{
${ }^{4}$ Disponível em http://www.baixarnogoogle.com/2012/05/jornal-o-globo-em-pdf-domingo-13-de.html. Acesso em 01/02/2013.
} 
$\begin{array}{llllllll}\mathbf{R} & \mathbf{E} & \boldsymbol{V} & \mathbf{I} & \mathbf{S} & \mathbf{T} & \mathbf{A} & \text { N. 24-2012.2-GLAUCIA GUIMARÃES }\end{array}$

Randolph Caldecott, reconhecido por Maurice Sendak como inventor do livro infantil ilustrado moderno - em especial, The house that Jack built, com imagens disponíveis em sites listados no Google Imagens -, é também apontado por Linden (2011, p.161) como precursor da justaposição de linguagens na literatura:

A obra de Caldecott assinala o início do livro ilustrado moderno. Ele concebeu uma engenhosa justaposição de imagem e palavra, um contraponto que nunca acontecera antes. Abstraem-se as palavras - e a imagem fala. Abstraem-se as imagens - e as palavras falam. Em suma, trata-se da invenção do livro ilustrado.

No entanto, uma das características dos livros infantis ainda era a de privilegiar a linguagem verbal escrita em detrimento da imagem, colocando-a apenas como ilustração.

Em 1919 Edy-Legrand, em seu livro Macao et Cosmage, consagra a inversão da relação vigente da predominância do texto escrito sobre a imagem no livro com ilustração. Nele o olhar do leitor é orientado para as imagens. Michel Defourny (apud LINDEN, 2011, p. 15), que fez o prefácio à edição de 2000, da editora francesa Circonflexe, diz: "De fato, essa é uma obra que privilegia explicitamente o visual, anunciando, em 1919, o livro ilustrado contemporâneo infantil”"

As décadas de 1950 e 60 constituem uma etapa significativa na origem histórica do livro contemporâneo com imagens. Neste período se almejava "ampliar o espaço e o status da imagem dentro do livro" e era anunciado "a importância do aspecto visual nos livros ilustrados contemporâneos" (LINDEN, 2011, p. 17). Então, em 1963, Maurice Sendak publica, pela Cosac Naify, Onde vivem os monstros. Este livro é considerado uma obra-prima, por introduzir "uma nova concepção da imagem, que passa a permitir representar o inconsciente infantil" (LINDEN, 2011, p. 17) e, de certa forma, distancia-se do caráter ilustrativo e pedagógico -, próprio do livro infantil.

Mas é no projeto editorial de François Ruy-Vidal e Harlin Quist, nos anos 1970, que as "imagens rompem deliberadamente com a funcionalidade pedagógica. Em face das imagens denotativas, cópias do real e suportes de aprendizado, emerge uma imagem inesperada com inúmeras ressonâncias simbólicas” (LINDEN, 2011, p. 17).

Esta rápida retrospectiva já nos permite apreciar a amplitude do desenvolvimento do livro infantil, cuja imagem está presente e articulada a outras linguagens. Além disso, nos possibilita pensar na produção de sentidos nos textos feitos para iPads e tablets. Estes, mais do que os impressos, incluem o som como matéria semiótica sempre presente nestes livros. 
$\begin{array}{llllllll}\mathbf{R} & \mathbf{E} & \boldsymbol{V} & \mathbf{I} & \mathbf{S} & \mathbf{T} & \mathbf{A} & \text { N. 24-2012.2-GLAUCIA GUIMARÃES }\end{array}$

Um bom exemplo de multimidiático é o The fantastic flying books of Morris Lessmore, de William Joyce, da Moonbot, animação que virou livro, publicado no Brasil pela Rocco. No $i P a d$, o aplicativo articula: história verbal, imagética e sonora, com narração oral, animação, música, movimento, interatividade e recursos diversos.

Por todas estas características, observa Cademartori (2012, p. 51):

[...] a produção literária infantil deste início de século mostra acentuada inclinação para transcender as fronteiras de gênero e também para estabelecer novas relações entre imagens e palavras. As ilustrações abandonaram o modesto papel de ficar a serviço do que relatam as palavras e passaram a constituir um outro texto, de natureza visual, que estabelece interação com o verbal. Assim, ambos se tornaram igualmente fundamentais no livro para crianças.

Neste sentido, Andruetto (2012) defende já no título de seu livro: "Por uma literatura sem adjetivos”. No sentido menosprezado, essa literatura não tem nada de infantil. São novos textos contemporâneos, mais complexos, que requerem novas leituras. E a partir destes textos literários infantis é possível estudar a articulação de linguagens para ler criticamente os diversos textos contemporâneos que optam pela intersemioticidade.

\section{A articulação de linguagens leitura de textos na universidade}

Como vimos, o desenvolvimento dos procedimentos de produção e de difusão de textos hoje possibilita cada vez mais que obras multimidiáticas se multipliquem, reunindo caracteres tipográficos, imagens e até mesmo sons na mesma página ou intervalo de tempo.

Por sua longa história em articular diversos materiais semióticos, a literatura infantil vem se configurando como uma forma de estudo da produção de sentidos na articulação de linguagens.

Neste viés, nas aulas de literatura infantil para a graduação da Faculdade de Formação de Professores, tomamos a articulação de linguagens destes textos para discutir diversas acepções. Uma delas diz respeito aos cânones de leitura e produção de textos relacionados à linguagem verbal, geralmente propostos nos livros didáticos de Língua Portuguesa. Diante da complexidade da articulação de linguagens na produção de sentidos, não há como elaborar uma gramática que a abarque. 
$\begin{array}{llllllll}\mathbf{R} & \mathbf{E} & \boldsymbol{V} & \mathbf{I} & \mathbf{S} & \mathbf{T} & \mathbf{A} & \text { N. 24-2012.2-GLAUCIA GUIMARÃES }\end{array}$

Considerando esta complexidade, também discutimos a suposição de que textos ilustrados são mais fáceis de serem lidos, como falamos na primeira seção deste artigo. Esta simplificação pode ser lida em Chauí (2003, p. 7) na crítica à docência "entendida como transmissão rápida de conhecimentos, consignados em manuais de fácil leitura para os estudantes, de preferência ricos em ilustrações e com duplicata em CD-ROM".

O livro Não vou dormir, de Christiane Gribel e Orlando é trabalhado para analisar o modo de articulação divergente entre imagem e palavra. A história traz a personagem de uma menininha que, obedecendo a ordem de sua mãe, vai para cama, garantindo que não está com sono. Mas as imagens mostram que suas pálpebras estão pesadas, mostrando o quarto sob o ponto de vista da menina.

A cada página a imagem mostrada representa o ângulo de visão da menininha se reduzindo, evidenciando que a menina cochila, enquanto afirma não estar com sono, como é possível observar nas páginas 6, 9 e 19 do original - e copiadas a seguir . O livro desencadeia uma potencialidade de sentidos através do modo de articulação divergente e com recursos expressivos da linguagem verbal e não-verbal - que acompanham, como um fade, o fechamento das pálpebras da menininha no escuro do quarto de dormir:

\section{Figura $2^{5}$}
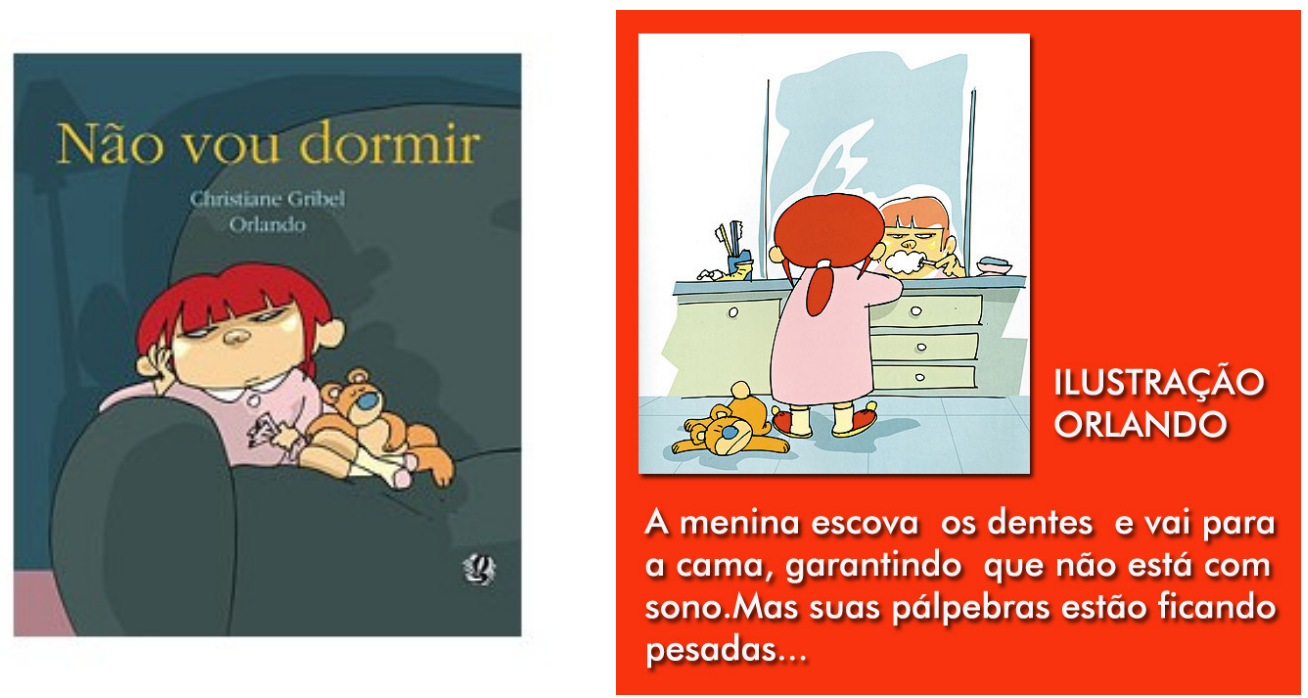

\footnotetext{
${ }^{5}$ Capa do livro e início a história. Disponível em: http://www.google.com.br/search?hl=ptBR\&rlz=1T4ADRA_ptBRBR426BR427\&q=N\%C3\%A3o+vou+dormir,+de+Christiane+Gribel\&um=1\&ie=UTF-8 (Google Imagem) Acesso a 10-12-2012.
} 


\section{SOLETR AS}

$\begin{array}{llllllll}\mathbf{R} & \mathbf{E} & \mathbf{V} & \mathbf{I} & \mathbf{S} & \mathbf{T} & \mathbf{A} & \text { N. 24-2012.2-GLAUCIA GUIMARÃES }\end{array}$

Figura $3^{6}$
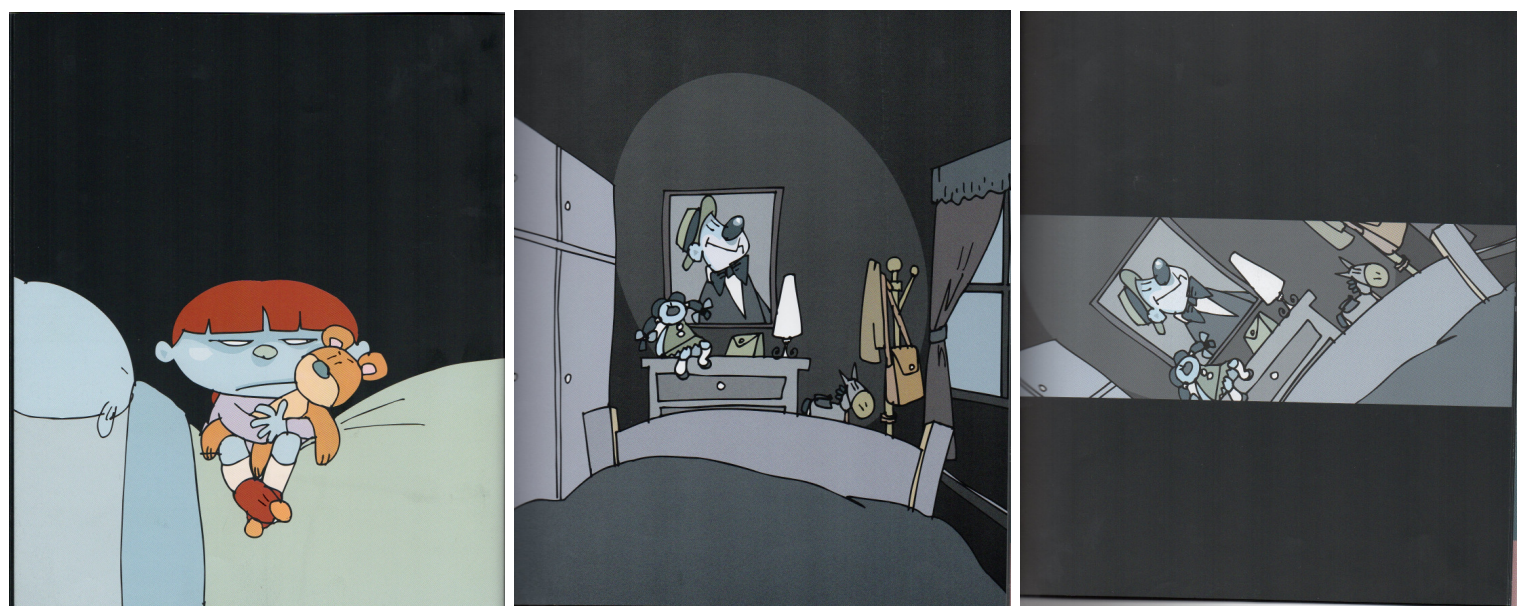

A partir do estudo das linguagens articuladas neste livro, experimentamos inserir sons ao livro, usando o Movie Maker. Foram feitos vários vídeos que "movimentam” as páginas do livro e incluem o som ou música atribuindo sentidos diferentes ao observado apenas com o livro em papel. De acordo com a compreensão de cada um dos alunos, músicas, sonoplastia iam modificando a história, produzindo outros efeitos de sentido. Para observar uma produção destas vale acessar o Youtube. ${ }^{7}$ Também partimos de um texto aparentemente simples para chamar a atenção para a complexidade característica das leituras possíveis na articulação de linguagens, com o intitulado "Tudo bem ser diferente" de Toddy Parr (2002), conforme figura 4, que corresponde às 7 e 4 do original:

Figura $4^{8}$
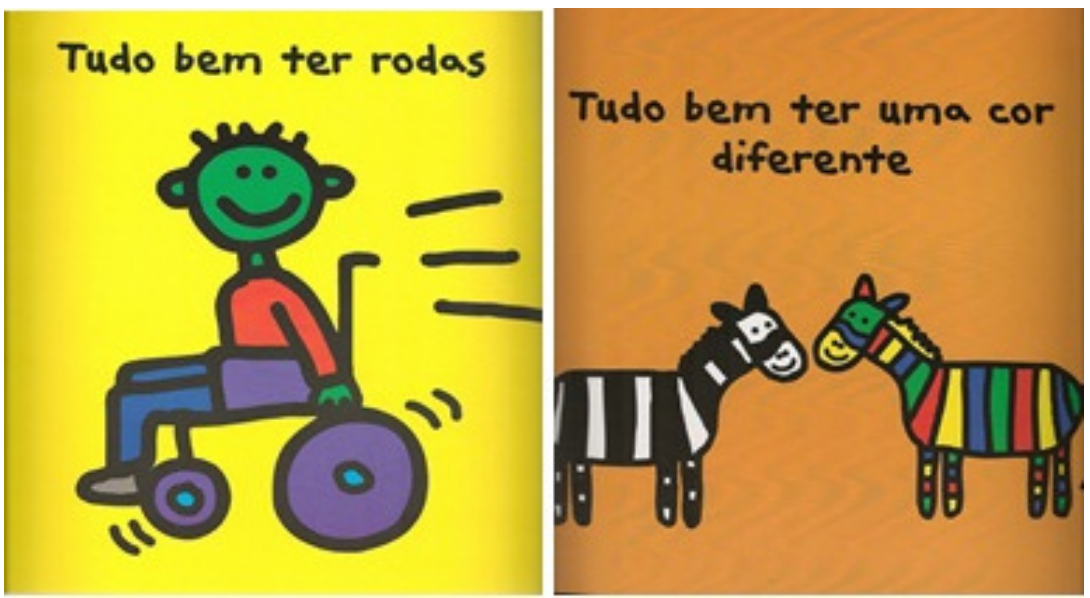

\footnotetext{
${ }^{6}$ Imagens escaneadas do livro do GRIBEL (2007, p. 6-9-19).

${ }^{7}$ Disponível em http://www.youtube.com/watch?v=a3Sp-Fb2Tg4. Acesso em 03/02/2013.

${ }^{8}$ Algumas das páginas deste livro encontram-se no blog http://emnapion.blogspot.com.br/2012/03/tudo-bem-serdiferente-todd-parr.html ou em formato de filme no YouTube http://www.youtube.com/watch?v=DgrFIgvF7KU
} 
$\begin{array}{llllllll}\mathbf{R} & \mathbf{E} & \boldsymbol{V} & \mathbf{I} & \mathbf{S} & \mathbf{T} & \mathbf{A} & \text { N. } 24-2012.2-\text { GLAUCIA GUIMARÃES }\end{array}$

Nele, a diferença é trabalhada como causa natural de preconceitos, abordando temas como deficiência física e sempre com uma ambiguidade positiva ("Tudo bem ter rodas" - o que alude também a carros, agilidade), preconceito racial ("Tudo bem ter uma cor diferente", sugerindo um colorido opcional), aparência (Tudo bem ter um dente a menos ou dois ou três)", com a ilustração de uma menina sem os dentes da frente indiciando fase de crescimento e não necessariamente a condição social que impossibilita tratamento dentário), dentre outros. Como alertam Silveira, Bonin e Ripoll (2010, p. 106) a maioria dos livros sobre o tema acaba reforçando ideias e preconceitos, "para situar a diferença e ensinar sobre ela, para dizer quem e como são os diferentes, para prescrever atitudes".

Com base neste livro, um dos alunos fez uma releitura do livro chamando a atenção não somente para as diferenças, como também para as desigualdades e para os desconectados. Esta releitura possui muitas páginas, mas para exemplificar, em uma delas há a frase "Tudo bem não ter tratamento dentário público" as ilustrações são um menino sorrindo com dentes cariados e outro, de classe média sorrindo na cadeira do dentista. Em outra página "Tudo bem entrar em fila" as ilustrações articuladas são duas: uma com crianças na fila da comida emergencial e outra com crianças na fila do Mc Donald's, como mostra a figura 7, a seguir:

Figura $7^{9}$

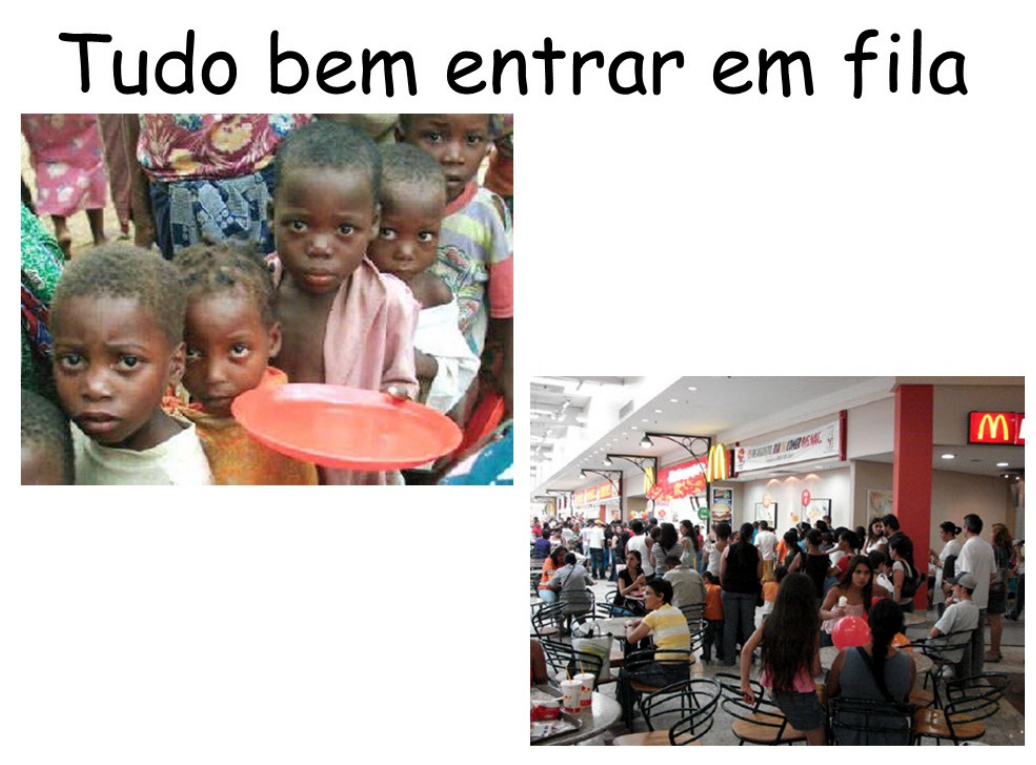

\footnotetext{
${ }^{9}$ Disponível em Google Imagem: http://www.google.com.br/search?q=fila+para+comer+na+\%C3\%A1 frica\&hl=pt-R\&tbo=d\&rlz=1T4ADRA_pt-. Acesso em 01 de janeiro de 2012.
} 


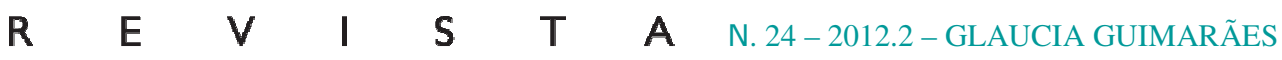

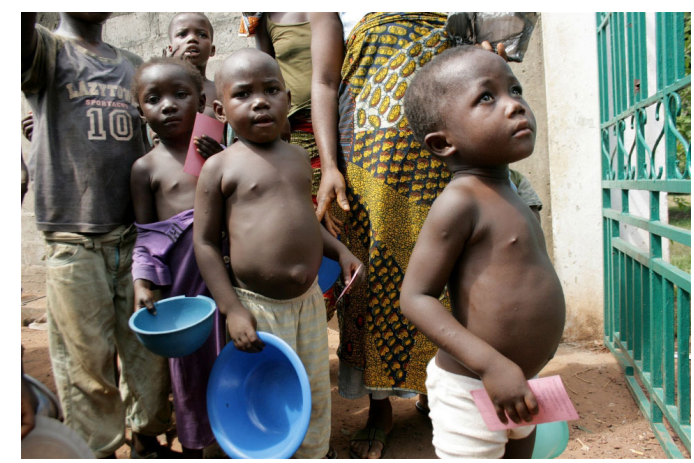

Como circulam socialmente os mais variados textos multimidiáticos, veiculados pelas tecnologias da informação e da comunicação, é possível afirmar a democratização do acesso a eles. Entretanto, as leituras destes mesmos textos tendem a não levar em conta a articulação das linguagens que os constituem, sobretudo como são orientados os sentidos para legitimar um hegemônico. Em outras palavras, é perfeitamente possível "ver" TV ou navegar na internet sem que estes movimentos sejam ancorados em uma leitura crítica dos sentidos e dos modos da sua circulação.

Em função da orientação de sentidos que as tecnologias da informação e da comunicação acabam produzindo, há os que ainda propõem a separação entre os textos que circulam socialmente e os escolares.

Seria indefensável qualquer proposta de manter a escola longe dos textos que pelos quais nos comunicamos na prática social. No entanto, o acesso aos textos não é suficiente. No contexto desta prática de pesquisa foi possível observar que apenas a presença ou a alusão aos textos multimidiáticos no espaço escolar é importante, mas não é suficiente para um trabalho para apropriação dos textos que articulam linguagens.

\section{Leituras à espera de leitores, nas instituições de ensino e na sociedade}

Como vimos, os textos contemporâneos são produzidos por linguagens articuladas. Em qualquer proposta de produção de sentidos, portanto, não é suficiente apenas a focalização de uma das linguagens em jogo, o que geralmente acontece nas instituições de ensino. Privilegiar a linguagem verbal escrita nas práticas de ensino pode contribuir para aumentar a lacuna entre a ponta da produção e a da recepção: entre textos e leituras.

Esta lacuna parece ser constituída por simplificações produzidas pela manutenção dos parâmetros de leitura relacionados à linguagem verbal escrita em "textos didáticos", no 
$\begin{array}{llllllll}R & \text { E } & \boldsymbol{V} & \mathbf{I} & \mathbf{S} & \mathbf{T} & \mathbf{A} & \text { N. } 24-2012.2-\text { GLAUCIA GUIMARÃES }\end{array}$

sentido de simplificados em nome da suposta clareza e objetividade. Em outras palavras, desde a circulação dos textos audiovisuais, é comum a suposição de que sua leitura seja mais fácil, como ressaltamos na segunda seção deste artigo.

Como também dissemos na introdução, com a popularização das TIC o acesso aos textos multimidiáticos aumentou. Entretanto, não há como afirmar que as leituras destes mesmos textos levem em conta a dança das linguagens que os constituem. É possível ver televisão, comunicar-se via internet e seus variados meios, sem que a produção e leitura destes textos sejam ancoradas em uma leitura crítica dos sentidos circulantes e dos modos da sua circulação.

Também é possível afirmar que a presença dos textos multimidiáticos no espaço escolar é condição necessária à formação de leitores críticos. Seria indefensável qualquer proposta de manter a escola alijada dos textos que circulam socialmente. No entanto, o acesso aos textos não é suficiente. É preciso pensar nos modos como eles têm sido inscritos nas práticas pedagógicas, superando as propostas voltadas para a manutenção dos "mesmos" conteúdos e gestos de leitura, tornados mais atraentes, lúdicos e, portanto, "modernos" (KELLNER, 2001).

Em conversas de professores, tendem a ser recorrentes propostas como: "usar um vídeo para motivar a discussão sobre temática X", "trabalhar de forma lúdica, com um jogo multimídia, o conceito matemático Y", "encontrar um texto na internet ou um programa de TV que trate do problema Z" etc. Não deixam de ser um princípio de ação, mas não podem se restringir a uma espécie de pílula edulcorada para informar, ensinar e, muitas vezes, conformar.

Defendemos que a instituição de ensino se constitua como espaço de reflexão acerca dos textos que circulam socialmente, dos modos pelos quais as linguagens são articuladas e dos efeitos de sentidos que produzem. Propomos uma reflexão desenvolvida a partir da leitura, objetivando a análise dos sentidos hegemônicos veiculados; enfim, um trabalho produzido coletivamente, a partir da discussão dos diferentes sentidos possíveis, dos pressupostos assumidos, dos vários lugares sociais e das múltiplas subjetividades, enfim, um novo texto que desmonte as tramas da interpretação legitimada socialmente.

Do nosso ponto de vista, literatura infantil é arte como resistência ao aprisionamento em que o presente nos confina, pensando novos sentidos para além dos hegemônicos, inventando novas maneiras de existir. 
$\begin{array}{llllllll}\mathbf{R} & \mathbf{E} & \boldsymbol{V} & \mathbf{I} & \mathbf{S} & \mathbf{T} & \mathbf{A} & \text { N. } 24-2012.2-\text { GLAUCIA GUIMARÃES }\end{array}$

Literatura, do nosso lugar de educadora, é vista como os poemas/pássaros de Quintana. Através delas podemos produzir novos sentidos e fazê-los voar para se alimentarem em outros sujeitos. Para nós, é por isso que a literatura, sua leitura e sua produção, são imprescindíveis. Abre-nos a possibilidade de nos lermos de outra forma, de vivermos variados lugares sociais, ao mesmo tempo em que nos permitem abrigar outras versões de nós mesmos, no esforço de melhor compreendermos a sociedade em que vivemos e com a qual (ainda) sonhamos.

\section{Referências bibliográficas:}

ALEXANDRINO, Helena. Helena. In: MORAES, Odilon; HANNING, Rona; PARAGUASSU, Maurício. Traço e prosa: entrevistas com ilustradores de livros infantojuvenis. São Paulo: Cosac Naify, 2012.

ANDRUETTO, Maria Teresa. Por uma literatura sem adjetivos. São Paulo: Pulo do gato, 2012.

BARRETO, R. G. Formação de professores, tecnologias e linguagens: mapeando novos e velhos (des) encontros. São Paulo: Loyola, 2002.

BARTHES, Roland. A câmara clara: nota sobre a fotografia. 3. ed. Rio de Janeiro: Nova Fronteira, 2011.

BARTHES, Roland. O prazer do texto. 3. ed. São Paulo: Perspectiva, 2002.

BARTHES, Roland. S/Z. Rio de Janeiro: Nova Fronteira, 1992.

CADEMARTORI, Ligia. O professor e a literatura para pequenos, médios e grandes. Belo Horizonte: Autêntica, 2012.

CANCLINI, N. Diferentes, desiguais e desconectados. Rio de Janeiro: Editora UFRJ, 2009.

CARAMICO, Thais. Para ler com as mãos: um passeio pelo universo dos Ipads. Revista Emília, setembro de 2012. Disponível em http://www.revistaemilia.com.br/mostra.php?id=43 Acesso em 15 de dezembro de 2012.

CASTAGNOLI, Anna. O nascimento de João Felpudo de Hoffmann a Edward Mãos de Tesoura. Revista Emília. Artigos Agosto 2012. Disponível em http://www.revistaemilia.com.br/mostra.php?id=229. Acesso em 15 de dezembro de 2012.

FAIRCLOUGH, N. Discurso e mudança social. Brasília: Editora da UNB, 2001.

GUIMARÃES, Glaucia. TV e educação na sociedade multimidiática: o discurso sedutor em imagem, som e palavra. Rio de Janeiro: Quartet, 2010. 


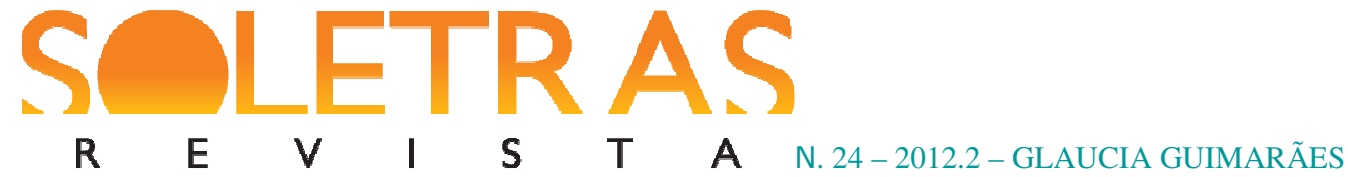

JOYCE, William. Os fantásticos livros voadores de Modesto Máximo. Rio de Janeiro: Rocco, 2012.

KELLNER, D. A cultura da mídia. Estudos culturais: identidade e política entre o moderno e o pós-moderno. Bauru, SP: EDUSC, 2001.

LINDEN, Sophie Van der. Para ler o livro ilustrado. São Paulo: Cosac Naify, 2011.

QUINTANA, Mário. Esconderijos do tempo. Porto Alegre: L\&PM, 1980.

NUNES, J. H. Aspectos da forma histórica do leitor brasileiro na atualidade. In: ORLANDI, E. P. (Org.). A leitura e os leitores. Campinas, SP: Pontes, 1998. p. 25-46.

ORLANDI, E. P. A linguagem e seu funcionamento: as formas do discurso. 5. ed. Campinas, SP: Pontes, 2009.

Efeitos do verbal sobre o não-verbal. Rua, 1, Campinas, SP, p.35-47, 1995.

- As formas do silêncio: no movimento dos sentidos. Campinas, SP: Editora da UNICAMP, 1992.

Terra à vista. Discurso do confronto: velho e novo mundo. São Paulo: Cortez; Unicamp, 1990.

Discurso e leitura. São Paulo: Cortez; UNICAMP, 1988.

SILVEIRA, Rosa M. Hessel; BONIN, Iara Tatiana; RIPOLL, Daniela. Ensinando sobre a diferença na literatura para crianças: paratextos, discursos científicos e discurso multicultural. Revista Brasileira de Educação. v. 15, n. 43 jan.-abr. 2010.

\section{La articulación de lenguajes en la lectura de textos en la universidad}

Resumen: En este artículo se discute la articulación palabra, imagen y sonido en la lectura de textos en la universidad. Basándose en las reflexiones sobre este tema, relata prácticas de lectura de textos de la literatura infantil, puesto que revelan gran legado en la articulación de lenguajes. El artículo está dividido en seis secciones. Al principio, indica la complejidad de los textos configurados a través de lenguajes. En la segunda sección, cuestiona el significado que las imágenes asociadas al texto escrito logren realizar lo que las palabras de por sí no lo puedan, facilitando su lectura. A partir de entonces, fundándose en el análisis crítico del discurso, caracteriza los modos de articulación de lenguajes en la producción y legitimación de los sentidos hegemónicos. En la siguiente parte se destacan el legado en la articulación de lenguajes revelada históricamente por los libros infantiles. La sección quinta expone una propuesta de lectura crítica de textos contemporáneos desarrollada en la universidad con los libros de literatura infantil. En sus consideraciones finales, reitera que la relación de los sujetos con el universo simbólico no se establece por una sola trayectoria - del verbo, de la 
imagen, o del sonido -, pero teniendo en cuenta su contexto histórico-social, a través de la articulación de estos lenguajes, sean ellos desarrollados dentro o fuera de las instituciones educativas. Es necesario, por lo tanto, trabajar con la articulación del sujeto con el universo simbólico, considerando la literatura infantil como resistencia al encarcelamiento en el que el presente nos mantiene pensando en nuevos sentidos más allá de los hegemónicos, inventando nuevas formas de existir.

Palabras clave: Articulación de lenguajes. Lectura. Imagen.

Recebido em: 28 de dezembro de 2012.

Aprovado em: 7 de janeiro de 2013. 